Zilka Spahić Šiljak, Zenica

\title{
PRVI MARS-OVCI U BOSNI U HERCEGOVINI: RELIGIJSKO OBRAZOVANJE NA UNIVERZITETU
}

Despotizam može i bez vjere, ali sloboda ne. (Alexis de Tokvil)

\section{Uvod}

Obrazovanje je stub svakog društva, a kako je danas većina društava multietnička i međusobno su snažnije povezana tehnološkim i ekonomskim napretkom, onda je interkulturalno obrazovanje najbolji način da se kultivira etos međusobnog razumijevanja i uvažavanja. Na koncu sloboda podrazumijeva izbor, uključujući i izbor vjerovanja ili nevjerovanja i vjerskog obrazovanja. Važan dio interkulturalnog obrazovanja je i religijsko obrazovanje koje, ako se postavi na temelje univerzalizma, može doprinijeti približavanju različitih svjetonazora.

Bosanskohercegovačko društvo je uvijek bilo multikulturno i religija je imala značajnu ulogu kako u privatnom tako i u javnom životu. Iako je religija u socijalizmu bila potisnuta na margine društvenog života, to ne znači da je društvo u potpunosti bilo sekularizirano. U privatnoj sferi kroz različite vrste običajnih i obrednih praksi religija je živjela i održavana kao važan dio identiteta i kulture. Religijsko obrazovanje u socijalizmu se odvijalo u crkvama i vjerskim zajednicama, a u školi se religija uglavnom spominjala kroz umjetnost, muziku i povijest. Nakon 1990-ih dolazi do revivalizma religije u javnom prostoru pa se još u jeku trajanja rata u Bosni i Hercegovini crkve i vjerske zajednice u saradnji s državnim institucijama angažiraju na uvođenju konfesionalnog vjeronauka u državne škole.

Posvemašnja politizacija religije tokom i nakon rata, ali i religizacija politike (Vrcan 2001; Andjelic 2003; Abazović 2006, Cvitković 2019) polariziraju građane i građanke na one koji zagovaraju povratak religije u privatnost i one koji smatraju da, iako država treba da je sekularna, društvo ne može biti sekularno i da je potrebno pronalaziti modalitete akomodacije religije u javnom prostoru. 
Jedan od malobrojnih sociologa religije akademik profesor dr. Ivan Cvitković, koji je svoju akademsku karijeru počeo na Fakultetu političkih nauka u Sarajevu, a kao profesor emeritus, nastavio na Akademiji nauka i umjetnosti Bosne i Hercegovine, u svojim radovima bavio se i još uvijek se bavi pitanjima religije, identiteta, sekularizma, sekularizacije, globalizacije i obrazovanja. Profesor Cvitković je dao veliki doprinos obrazovanju, i to ne samo na Fakultetu političkih nauka na kojem je podučavao brojne generacije studenata već i na prvom Magistarskom programu Religijskih studija u Bosni i Hercegovini koji je pokrenut na Univerzitetu u Sarajevu 2007. godine.

\section{Religijsko obrazovanje na univerzitetu u 21. stoljeću}

Iako su teorije sekularizacije predviđale smanjenje utjecaja religije i identifikacije sa religijom (Berger 1996), kraj 20. stoljeća i početak novog milenija su pokazali da je društvena zbilja mnogo kompleksnija od binarnih stavova o sekularizaciji i desekularizaciji. Na globalnoj sceni jačaju fundamentalistički religijski pokreti kao odgovor na globalizacijske tokove koji su osiromašili zemlje Trećeg svijeta, a brojne fluktuacije stanovništva s Istoka na Zapad sa kompartmentaliziranim politikama identiteta otvorile su prostor da se religija snažnije koristi u svrhu homogenizacije i mobilizacije za određene političke ciljeve. Zagovarajući načelo "kraja velikih narativa", "metateorija" i nepostajanja neprikosnovene istine koja ima univerzalnu važnost, postmodernizam je doveo u pitanje maksimalističke zahtjeve religija za posjedovanjem apsolutne istine, ali je na taj način došlo do slabljenja općih etičkih vrijednosti i pojave hedonizacije i relativizacije.

Kao jedan od odgovora na eklezijastički maksimalizam i postmodernistički relativizam, nudi se kao alternativa dijalog između različitih religija $\mathrm{i}$ svjetonazora. Ova alternativa može olakšavati suživot u multietničkim i multireligijskim društvima, a dugoročno biti osnova uspostavljanja religijskog i etičkog utemeljenja univerzalnih vrijednosti kao što su sloboda, pravda, tolerancija, solidarnost i drugo (Spahić Šiljak 2018). No, da bi se istinski dijalog uspostavio i bio djelotvoran, potrebno je uključiti religiju u obrazovanje i istraživanje na univerzitetima. Znanstveni pristupi i metode istraživanja religije kao društvenog, političkog i kulturnog fenomena mogu pokazati značaj religije i kao individualne i socijalne stvarnosti. Na ovaj način bi se religija sačuvala od opasnosti devijacija sekularizma i fundamentalizma.

Znanstveni pristup religiji je inherentno kritički, a ne apologetski, i kao takav smanjuje maksimalističke zahtjeve religija za posjedovanjem svih odgovora i olakšava međusobno susretanje različitih religijskih i nereligijskih 
svjetonazora kroz interkulturalni i međureligijski dijalog. Na prigovore da se smisao vjerovanja ne može proučavati znanstvenom, racionalno-diskurzivnom metodom, Đuro Šušnjić (1998) odgovara da istraživači religije ne pitaju da li određeni obred ima smisla, već kakav smisao ima taj obred za ljude koji ga prakticiraju. Znanstveni pristup ne slabi religiju, kako se obično misli, već je može oslobađati od ideološkog balasta koji se javlja zbog isprepletenosti religije sa politikom, kulturom, nacijom i državom.

Iako je na univerzitetima u Americi i Zapadnoj Evropi obrazovanje, a napose visoko obrazovanje, prilično sekularizirano, u drugoj polovici 20. stoljeća se otvaraju religijske studije ili kao zasebni programi ili kao dio globalnih studija, međunarodnih odnosa, ljudskih prava i slično. Pokazalo se da modernost ne isključuje nužno religioznost (Davie 2007) i da je ljudima potrebna duhovnost te da im religija kroz različite obredoslovne prakse pomaže pronaći smisao života (Gavrilović 2008). Na koncu, globalna kretanja i mreža novih komunikacijskih kanala donose nove izazove postmodernističkoj viziji svijeta, jer se pojavljuju različite vrste fundamentalističkih pokreta koji nude alternativu rastopljenim, nestabilnim i fluidnim identitetima multikulturalnih zajednica (Castells 2002).

Pokreću se vladini programi za dijalog sa religijama kako bi se bolje razumjele ideološke pozadine religijski motiviranih pokreta s ambivaletnim religijskim porukama o nasilju (Applebey 2000). Zbog toga se pomaže rad novih programa religijskih studija kako bi se osposobile nove generacije znanstvenika koje će interdisciplinarno analizirati društvenu i političku zbilju. Tako je i Američka vlada podržala prijedlog Državnog univerziteta u Arizoni da se pokrene dvogodišnji Magistarski program religijskih studija (MARS) u Sarajevu.

Profesor Stephen Batalden sa Državnog univerziteta Arizona je s tom idejom došao u Sarajevo 2005. godine i u saradnji s Američkom ambasadom, Centrom za interdisciplinarne postdiplomske studije (CIPS, a danas CIS) kojim je rukovodio prof. dr. Zdravko Grebo te s IMIC centrom "Zajedno" koji je vodio Marko Oršolić i Fakultetom političkih nauka iz Sarajeva u ime kojeg su se inicijativi pridružili prof. dr. Ivan Cvitković i prof. dr. Dino Abazović, organizirao je konferenciju pod nazivom "Religijsko obrazovanje u 21. stoljeću”. Na konferenciji su okupljeni profesori iz Bosne i Hercegovine, regije, ali i drugih evropskih zemalja, kako bi se diskutiralo o sadržaju i načinu organiziranja Magistarskih religijskih studija (MARS) na Univerzitetu u Sarajevu. Vrlo je važno bilo okupiti relevantne glasove iz Bosne i Hercegovine koji su shvaćali koliko je u postsocijalističkom i postratnom kontekstu, u kojem je religija imala i još uvijek ima vrlo značajnu ulogu, potrebno otvoriti prostor za znanstveno propitivanje religije. 
Tadašnji rektor Univerziteta u Sarajevu prof. dr. Hasan Muratović i prof. dr. Zdravko Grebo su potpisali Sporazum o pokretanju MARS-a sa Državnim univerzitetom Arizona i Američkom ambasadom, a kasnije i s Univerzitetom u Oslu. Na temelju Sporazuma, odabrana je i grupa mladih znanstvenika, magistara i doktoranata filozofije, religije, historije, pedagogije, rodnih studija i književnosti (Vuk Miljanović, Entoni Šeperić, Zilka Spahić Šiljak, Sead Fetahagić, Nedžad Grabus, Amel Alić i Amra Pandžo) koji su 2006. godine proveli semestar na Državnom univerzitetu Arizona i, u saradnji s njihovim profesorima religijskih studija, kreirali silabuse za MARS. Ukupno je pripremljeno 14 silabusa. ${ }^{1}$

Magistarske religijske studije bile su zasnovane na principima komparativnosti i interdisciplinarnosti, uvažavajući i teološke uvide. Većina predmeta je kreirana tako da se komparativno (sociološki, historijski, antropološki, filozofijski i teološki), ali i interreligijski raspravlja o zadatim temama i pitanjima.

Senat Univerziteta u Sarajevu je 2007. godine donio odluku da prof. dr. Ivan Cvitković bude direktor MARS-a, na čelu Vijeća Programa u sastavu: prof. dr. Mile Babić, prof. dr. Zdravko Grebo, prof. dr. Fikret Karčić, prof. dr. Enes Karić, prof. dr. Rešid Hafizović, dr. Zilka Spahić Šiljak, dr. Taida Šarkinović i mr. Dino Abazović. Od tada počinje moja intenzivna saradnja sa prof. dr. Cvitkovićem.

U akademskoj zajednici postoje ljudi koji liderske funkcije obnašaju silom nametnutog autoriteta ili pak autoritet grade dostojanstveno i budu prihvaćeni s uvažavanjem kao što je bio slučaj sa profesorom Cvitkovićem. Kao sociolog religije, nastojao je interdisciplinarnim pristupom osigurati da se $u$ propitivanje religije kao društvenog fenomena podjednako uključe i teološka

\footnotetext{
${ }^{1}$ Silabusi za predmete MARS programa pripremljeni u saradnji sa profesorima Državnog univerziteta Arizona: 1. Sociologija religije sa metodologijom (voditelji: prof. dr. Ivan Cvitković i dr. Dino Abazović) 2. Religije suvremenog svijeta (voditelji: prof. dr. Ivan Cvitković i mr. sci. Sead Fetahagić), 3. Ritual, simbol i mit (voditelji: prof. dr. Alexandar Agdjanian, Moskva, i dr. Nedžad Grabus), 4. Religija i rod (voditeljice: prof. dr. Jasminka Babić Avdispahić i dr. Zilka Spahić) 5. Religija, nasilje i rješavanje konflikta (voditelji: prof. dr. John Carlson i mr. sci Amra Pandžo) 6. Zapadne religijske tradicije (voditelji: prof. dr. Rešid Hafizović i dr. Vuk Miljanović) 7. Klasična islamska misao (voditelji: prof. dr. Enes Karić i dr. Nedžad Grabus), 8. Religija i nacionalizam u jugoistočnoj Evropi (voditelji: prof. dr. Stephen Batalden i mr. sci Sead Fetahagić), 9. Religija i ljudska prava (voditelji: prof. dr. Zdravko Grebo, dr. Zilka Spahić Šiljak i dr. Dino Abazović) 10. Savremene religijske teorije (voditelji: Alexandar Agadjanian i dr. Vuk Miljanović) 11. Kristologija od perioda prosvjetiteljstva (voditelji: prof. dr. Mile Babić i mr. sci Entoni Šeperić), 12. Religija i obrazovanje (voditelji: Brian Gates, Velika Britanija, i dr. Amel Alić) 13. Religija i socijalna pravda (voditelji: prof. dr. Joel Gereboff, SAD, i mr. sci. Amra Pandžo) 14. Religija i film: Istraživanja u popularnoj kulturi (voditelji: prof. dr. Mark Woodward i mr. sci. Entoni Šeperić). Naknadno je dodat još jedan predmet, Komparativno religijsko pravo, koji je vodio prof. dr. Fikret Karčić.
} 
učenja monoteističkih religija, pa su tako na Religijskim studijama predavali sociolozi, filozofi, historičari, teolozi i drugi. Važno je bilo da se različite argumentacije sučeljavaju, da se pitanja religije elaboriraju iz različitih perspektiva, jer se samo tako može dobiti cjelovitija slika vrlo kompleksne društveno-političke zbilje Bosne i Hercegovine.

\section{MARS-ovci za multireligijsko obrazovanje}

Prva generacija studenata Religijskih studija ${ }^{2}$ upisana je u akademskoj 2007-2009. godini, a druga u akademskoj 2010-2012. godini. Konkurs je bio otvoren za studente primarno društvenog i humanističkog opredjeljenja, uključujući i teologe koji žele istraživati pitanja religije i religijskih identiteta u savremenom društvu. S obzirom na to da je program bio interdisciplinarne prirode, studentima su otvorene mogućnosti rada u državnim institucijama, nevladinim organizacijama, vjerskim zajednicama, školama i slično.

Studenti su naglašavali, ponekad šaljivo, a ponekad vrlo ozbiljno, da oni kao polaznici MARS-a (Magistarske religijske studije) simbolički i jesu marsovci - pioniri koju pokušavaju mijenjati društvenu stvarnost kroz obrazovanje. Oni u etnički podijeljenom bosanskohercegovačkom društvu promoviraju interkulturalno i međureligijsko učenje i razumijevanje, i to tako da obrazovanje uključuje, a ne da isključuje one s kojima se ne slažu, da obrazovanje potiče na dijalog i razumijevanje, a ne da zatvara vidike $\mathrm{i}$ horizonte slobode $\mathrm{i}$ razuma. S obzirom na to da je konfesionalni vjeronauk postao dio integralnog nastavnog plana i programa u većini škola, a da su predmeti "Kultura religija" i "Etika" bili zastupljeni samo u nekoliko škola u Kantonu Sarajevo i Brčko distriktu, prve generacije MARS-a su educirane da unesu nove dimenzije multireligijskog obrazovanja kako u konfesionalni vjeronauk tako i u zasebne predmete "Kultura religija" i "Etika".

Profesor Cvitković je, i kroz svoja predavanja i u neformalnim aktivnostima i razgovorima, jasno isticao svoju opredijeljenost za nekonfesionalno obrazovanje u državnim školama kao najprimjereniji vid obrazovanja u sekularnom postsocijalističkom društvu. Ipak, uvažavajući društveno-političku klimu i stanje u školama, znao je da je jedini način za promjenu otvaranje

\footnotetext{
${ }^{2}$ Prva generacija studenata upisanih na MARS u akademskoj 2007-2009. godini: 1. Abrahamsdotter, Emina (Švedska), Aljević, Vildana (BiH), Brkić, Marko Antonio (BiH), Crnjanski, Katarina (Srbija), Crnovršanin, Adisa (BiH), Gluhić, Muhammed (BiH), Grujić, Marija (Srbija), Hadžić, Sedžida (BiH), Hasečić, Maida (BiH), Imamović, Samed (BiH), Katava, Božana (BiH), Kupusović, Amer (BiH), Lasić, Ivan (BiH), Lubura, Nikica (BiH), Ljubić, Tatjana (Srbija), Ramić, Zineta (BiH), Resić, Mersiha (BiH), Pekmezović, Naida (BiH), Šeta, Đermana (BiH) i Zimjakova, Suzana (Slovačka).
} 
vrata dijaloga, posebno s onima koji su smatrali da je konfesionalni vjeronauk pravo izbora roditelja i djece i da se treba odvijati u školi. Mudri ljudi uvijek prate znakove svoga vremena i nastoje djelovati tako što uvažavaju vrijeme, potrebe i zahtjeve konteksta u kojem žive. Profesor Cvitković je upravo tako i postupao kao mudar čovjek i akademik s integritetom. Nije želio nikome ništa nametati, već dijaloški doći do rješenja. Znao je da sve što se silom nametne ne može opstati dugo jer će ga zamijeniti neko drugo silom nametnuto rješenje. Isticao je da samo ono što ljudi zajedno ispregovaraju i oko čega se slože da je važno za njih i zajednicu u kojoj žive ima šanse da se razvije kao dugoročno rješenje. Tako je bilo i sa religijskim obrazovanjem.

Među studentima je bilo i teologa koji su ili predavali konfesionalni vjeronauk ili su to namjeravali nakon završenog studija. Stoga je kroz MARS program profesor Cvitković nastojao promicati važnost interkulturalnog $\mathrm{i}$ multireligijskog pristupa u predstavljanju drugih tako što je stalno insistirao na tome da se drugome omogući da sebe predstavi, a ne da ga predstavljamo iz svoje redukcionističke vizure.

Profesor Cvitković je, kroz svoje predmete "Sociologija religije s metodologijom" i "Religije suvremenog svijeta", podsticao studente ne samo da nauče osnove o religijskim tradicijama koje su prisutne u Bosni i Hercegovini već i da obavezno posjete vjerske objekte, razgovaraju sa predstavnicima crkava i vjerskih zajednica i njihovim članovima.

Vjeru u Boga ili transcendentno, podsjećao je profesor Cvitković, ne možemo niti trebamo mjeriti, jer ne postoje objektivno mjerljivi parametri za to. Stoga je naglašavao da vjernike nikada ne treba pitati zašto vjeruju ili prakticiraju određeni obred, jer to sociologe religije ne zanima, već ih treba pitati kakav smisao daju njihovom životu, da li i na koji način im pomažu da se nose s izazovima života, na koji način utječu na njihove političke stavove, opredjeljenja i identitete.

Pored toga, profesor Cvitković je iznova napominjao da je važno biti što objektivniji u znanstvenom pristupu religiji i ne unositi svoje predrasude $\mathrm{u}$ propitivanje i istraživanje. Sjećam se da se, tokom jednog seminara koji je držao profesor Cvitković sa prvom generacijom studenata, raspravljalo o tome da li vjernik/-ica može objektivno istraživati religiju, odnosno da li može napraviti potreban znanstveni odmak. Profesor je navodio stavove sociologa religije koji su smatrali da je lakše biti objektivan ako istraživač/-ica ne pripada religiji koju istražuje. Na to mu je jedan od studenata postavio pitanje: da li je znanstvenik koji nije religiozan a priori objektivan? Profesor Cvitković je odgovorio da nema garancija za objektivnost te da i nereligiozan istraživač/ ica može imati predrasude prema vjernicima jer i vjernici i oni koji ne vjeruju 
u Boga su socijalizirani u određenom kulturološkom miljeu tako da kontekst i kultura u kojoj su odrasli neminovno utječu na njihov način razmišljanja i njihove stavove. Ipak, dodao je da nereligiozni znanstvenici imaju manje poteškoća prihvatiti drugoga, i religioznog i nereligioznog, dok se često događa da su vjernici socijalizirani ekskluzivistički - priznaju samo svoju religiju kao jedinu ispravnu i samo taj put kao jedini put spasenja.

Na kraju, profesor Cvitković je i svojim radom na Fakultetu političkih nauka u Sarajevu i na Magistarskom programu religijskih studija (MARS) pokazao da je znanstvenik i čovjek dijaloga. Vjerovao je da je jedini način za istinsku promjenu učenje i susret s drugim i drugačijim. Svaki susret donosi nova saznanja, iskustva i doprinosi duhovnom zrenju i jasnijem pogledu na stvarnost. Profesor Cvitković je stoga i kroz svoje radove i knjige uvijek išao u susret drugom i znatiželjno, ali i sa zebnjom da li će biti dovoljno pravedan u predstavljanju svjetonazora kojem ne pripada. To je i naglasio na početku svoje knjige Moj susjed musliman (2011) citirajući engleskog pisca Williama Hazlitta. Odgovorna osoba uvijek propituje sebe i svoje stavove i nastoji dati punu sliku o pitanju ili fenomenu koji obrađuje, a profesor Cvitković je znanstvenu odgovornost pokazao u svojim radovima i radu sa studentima.

\section{Literatura}

Abazović, D. (2006), Za naciju i boga: sociološko određenje religijskog nacionalizma, Magistrat - University Press, Sarajevo.

Andjelic, N. (2003), Bosnia and Herzegovina, the End of Legacy, Frank Cass, London. Appleby, S. (2000), The Ambivalence of Sacred: Religion, Violence and Reconciliation, Rowman\&Littlefield, New York / Oxford.

Berger, P. (1996), The Secularism in Retreat, The National Interest, Vol. 46, str. 3-12.

Castells, M. (2002), Informacijsko doba: ekonomija, društvo i kultura, Svezak II, Moć identiteta, Golden Marketing, Zagreb.

Cvitković, I. (2011), Moj susjed musliman, Školska knjiga, Zagreb.

Cvitković, I. (2019), Religija u raljama politike, Akademija nauka i umjetnosti Bosne i Hercegovine, Sarajevo.

Davie, G. (2007), The Sociology of Religion, Sage Publication.

Gavrilović, D. (2008), Moral i religija u savremenom društvu, Filozofski fakultet, Niš.

Spahić Šiljak, Z. (2018), Živi vrijednosti: globalni etos u lokalnom kontekstu Bosne i Hercegovine, TPO Fondacija, Sarajevo.

Šušnjić, Đ. (1998), Religija I, Čigoja štampa, Beograd.

Vrcan, S. (2001), Vjera u vrtlogu tranzicije, Dalmatinska akcija, Split. 